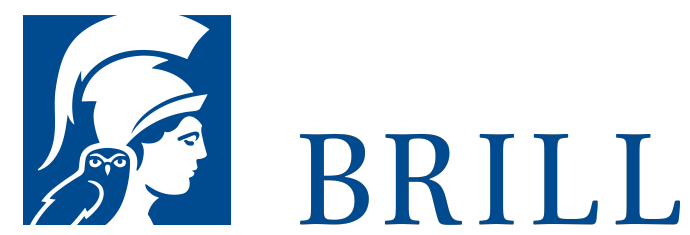

\title{
Moralische Dilemmata als wahre Widersprüche
}

Argumente für eine dialethistische Semantik im moralischen Diskurs

\section{Author: Helen Bohse-Nehrig}

Moralische Dilemmata lassen sich als Situationen charakterisieren, in denen sich eine Person zwei gleich starken moralischen Verpflichtungen gegenübersieht, die nicht beide zugleich erfüllt werden können. Mit diesen Situationen ist eine intuitiv gespürte Widersprüchlichkeit verbunden: Wofür sich die Person auch entscheidet, immer scheint sie damit zugleich etwas moralisch Falsches zu tun. In diesem Buch wird die spürbare Widersprüchlichkeit auf einen tatsächlichen logischen Widerspruch zurückgeführt, und es wird eine Lösung für dieses theoretische Problem moralischer Dilemmata entwickelt, die in der Revision der klassischen Semantik im Sinne des Dialethismus - also der These, dass sich Wahrheit und Falschheit nicht ausschließen - besteht. Ziel ist es zu zeigen, dass eine parakonsistente Lösung für das Problem moralischer Dilemmata, derzufolge wir es in diesen Situationen mit wahren Widersprüchen zu tun haben, eine ernst zu nehmende Alternative ist, die mindestens gleichberechtigt neben anderen Ansätzen steht - wenn sie sich nicht sogar in vielen Punkten als plausibler erweist.

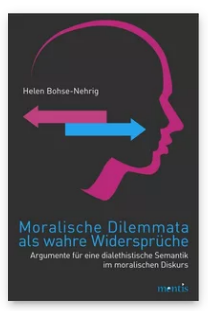

Pages: 190

Seiten

Language:

German

Subjects:

General,

Philosophy

Publisher: Brill | mentis

E-Book (PDF)

Released online:

o1 Jun 2013

ISBN: 978-3-

89785-967-8

List price

Paperback

Publication date:

o1 Jun 2013

ISBN: 978-3-

89785-808-4

List price 
For more information see brill.com

Order information: Order online at brill.com +44330 333 0049 | customerservices@brill.com Submission information: brill.com/authors

Titles published by Brill | Fink, Brill | mentis or Brill | Schöningh: +49(o)715413279216| brill@brocom.de 